\title{
Feasibility analysis of the use of anterior screw fixation in the treatment of pediatric odontoid fracture
}

\author{
Haicheng Dou, Chenglong Xie, Sipin Zhu, Xiangyang Wang, Qishan Huang, Feiya Zhou \\ Department of Orthopaedics, The Second Affiliated Hospital and Yuying Children's Hospital of Wenzhou Medical University, Zhejiang Spine \\ Surgery Center, Zhejiang Provincial Key Laboratory of Orthopaedics, Wenzhou, China \\ Contributions: (I) Conception and design: Q Huang, F Zhou; (II) Administrative support: X Wang; (III) Provision of study materials or patients: H \\ Dou; (IV) Collection and assembly of data: S Zhu; (V) Data analysis and interpretation: C Xie; (VI) Manuscript writing: All authors; (VII) Final \\ approval of manuscript: All authors. \\ Correspondence to: Qishan Huang. Department of Orthopaedics, The Second Affiliated Hospital and Yuying Children's Hospital of Wenzhou Medical \\ University, Zhejiang Spine Surgery Center, Zhejiang Provincial Key Laboratory of Orthopaedics, 666, Oushi Road, Dongtou District, Wenzhou \\ 325027, China. Email: hqshaq@126.com; Feiya Zhou. Department of Orthopaedics, The Second Affiliated Hospital and Yuying Children’s Hospital \\ of Wenzhou Medical University, Zhejiang Spine Surgery Center, Zhejiang Provincial Key Laboratory of Orthopaedics, 666, Oushi Road, Dongtou \\ District, Wenzhou 325027, China. Email: feiyazhou@yeah.net.
}

Background: This study aimed to determine the feasibility of using anterior percutaneous screw fixation to treat odontoid fractures in children of different ages based on computed tomography (CT) measurements.

Methods: A total of 176 children were enrolled and divided into 3 groups: group A (<6 years of age; 18 males and 22 females), group B (6 to 12 years old; 40 males and 35 females), and group C (12 to 18 years old; 34 males and 27 females). Using 2-dimensional CT reconstruction technology, we measured the children's odontoid parameters, including the coronal external diameter of the base of the odontoid process, the sagittal external diameter of the base of the odontoid process, the length of the odontoid process, the height of the axis vertebral body, and the angle between the axial line of the odontoid process and the vertical line of the anterosuperior border of the $\mathrm{C} 3$ vertebral body.

Results: The mean coronal external diameter of the odontoid process base in children under 6 years old was $4.21 \pm 1.62 \mathrm{~mm}$, which was not sufficient to accommodate a single screw. Among children aged 6 to 12 years old, this parameter varied widely, and the mean diameter was $5.50 \pm 2.80 \mathrm{~mm}$. In the 12 - to 18 -yearold group, the diameter was $8.64 \pm 1.68 \mathrm{~mm}$, which is similar to that of adults. The values of the total height of the axis, and the angle between the axial line of the and the vertical line of the anterosuperior $\mathrm{C} 3$ vertebral body border were lower than those for adults.

Conclusions: The percutaneous odontoid screw fixation technique is not recommended for children under 6 years old. For children aged 6 to 18 years old, this technique is feasible, but individual differences must be considered preoperatively. Selecting the appropriate screw diameter, length, and angle according to the actual CT measurement result is critical.

Keywords: Children odontoid; percutaneous fixation; hollow screw

Submitted Feb 23, 2021. Accepted for publication Apr 20, 2021.

doi: $10.21037 /$ tp-21-101

View this article at: http://dx.doi.org/10.21037/tp-21-101

\section{Introduction}

Odontoid process injury is reported in $80 \%$ of cases of vertebral lesions in children under 8 years old $(1,2)$. In recent years, minimally invasive surgical techniques have undergone rapid development. Anterior screw fixation has become a successful and widely established treatment option for odontoid fractures in adults. This technique has many advantages compared with traditional surgery (3-5). 

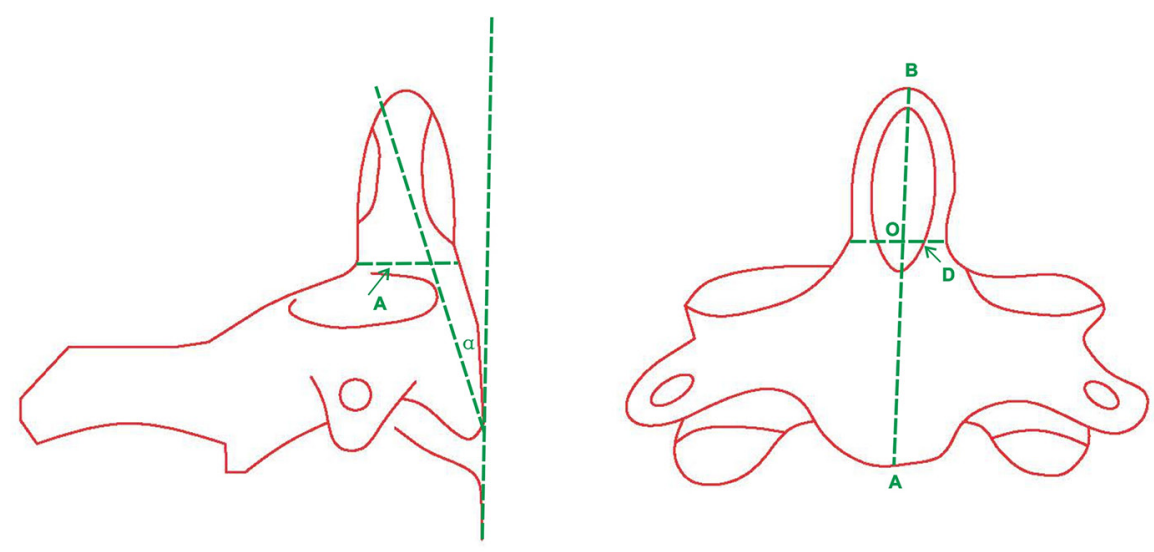

Figure 1 Measurement sketch of several parameters. D, the coronal external diameter of the base of the odontoid process; A, the sagittal external diameter of the base of the odontoid process; OB, the length of the odontoid process; $\mathrm{AB}$, the height of the axis vertebral body; $\left(\alpha^{\circ}\right)$, the angle between the axial line of the odontoid process and the vertical line of the anterosuperior border of the C3 vertebral body.

For instance, it eliminates the need for autologous bone grafts, extends the fusion range, and preserves the range of motion and axial rotation (6). For children, many factors, such as age, sex, and growth and developmental stage, need to be considered in the use of anterior screw fixation. Moreover, few related studies have been performed to date. A study by Fernandes et al. (7) involving children between the ages of 6 and 12 years found that anterior screw fixation is feasible for this age group. However, such a study has yet to be conducted on children under 6 years old or above 12 years old.

Therefore, in this study, we enrolled children from specific age groups ( $<6$ years old, 6 to 12 years old, and 12 to 18 years old) and determined the feasibility of using anterior percutaneous screw fixation in the treatment of these children based on computed tomography (CT) measurements. We hope that our research results based on a large sample size can serve as a morphological reference and will improve the application of anterior percutaneous screw fixation in children.

We present the following article in accordance with the STROBE reporting checklist (available at http://dx.doi. org/10.21037/tp-21-101).

\section{Methods}

\section{Study participants}

The clinical records of children who were treated at our hospital between 2009 and 2020 were retrospectively reviewed $(n=436)$. All the children had undergone CT examination following spinal trauma, the results of which were normal. The criterion for inclusion in the study was a clear CT image. Children with congenital diseases such as scoliosis, tumors, hemivertebral deformity, and ankylosing spondylitis were excluded. Eventually, 176 eligible patients were included in the study including 92 males and 84 females. According to the stage of development, each patient was assigned to 1 of the following groups: group A ( $<6$ years old, $n=40,18$ males and 22 females), group B ( 6 to 12 years old, $\mathrm{n}=75,40$ males and 35 females), and group $\mathrm{C}$ (12 to 18 years old, $\mathrm{n}=61,34$ males and 27 females).

All procedures performed in this study involving human participants were in accordance with the Declaration of Helsinki (as revised in 2013). The study was approved by Ethics Committee of the Second Affiliated Hospital of Wenzhou Medical University (No.: 2021-K-09-01).

\section{CT examination}

Using 2-dimensional CT reconstruction technology, we measured the children's odontoid parameters including the coronal external diameter of the base of the odontoid process (D), the sagittal external diameter of the base of the odontoid process $(\mathrm{A})$, the length of the odontoid process $(\mathrm{OB})$, the height of the axis vertebral body $(\mathrm{AB})$, and the angle between the axial line of the odontoid process and the vertical line of the anterosuperior border of the $\mathrm{C} 3$ vertebral body $(\alpha)\left(^{\circ}\right.$ ) (Figures 1,2$)$. 


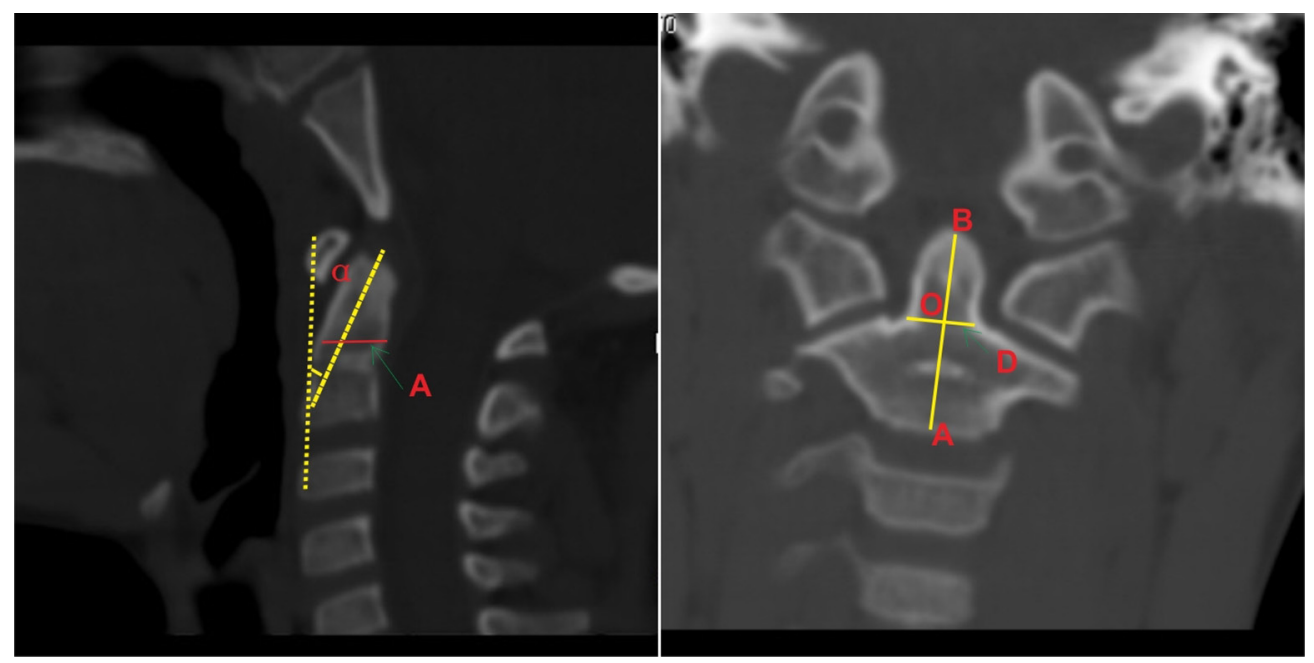

Figure 2 CT measurement diagram of several parameters. D, the coronal external diameter of the base of the odontoid process; A, the sagittal external diameter of the base of the odontoid process; OB, the length of the odontoid process; $\mathrm{AB}$, the height of the axis vertebral body; $\left(\alpha^{\circ}\right)$, the angle between the axial line of the odontoid process and the vertical line of the anterosuperior border of the C3 vertebral body.

Table 1 Measurement results of various parameters

\begin{tabular}{lccc}
\hline & Group A (<6 years) & Group B (6 to 12 years) & Group C (12 to 18 years) \\
\hline Parameter & 40 & 75 & 61 \\
D $(\mathrm{mm})$ & $4.21 \pm 1.62$ & $5.50 \pm 2.80$ & $8.64 \pm 1.68$ \\
A $(\mathrm{mm})$ & $4.40 \pm 1.93$ & $6.56 \pm 1.98$ & $9.50 \pm 1.91$ \\
OB $(\mathrm{mm})$ & $3.34 \pm 0.62$ & $5.90 \pm 0.80$ & $9.90 \pm 1.71$ \\
AB $(\mathrm{mm})$ & $12.69 \pm 2.20$ & $16.41 \pm 6.52$ & $18.69 \pm 1.98$ \\
$\left(\alpha^{\circ}\right)$ & $19.71 \pm 1.85$ & $21.49 \pm 2.18$ & $22.06 \pm 1.88$ \\
\hline
\end{tabular}

$\mathrm{D}$, the coronal external diameter of the base of the odontoid process; $\mathrm{A}$, the sagittal external diameter of the base of the odontoid process; $\mathrm{OB}$, the length of the odontoid process; $\mathrm{AB}$, the height of the axis vertebral body; $\left(\alpha^{\circ}\right)$, the angle between the axial line of the odontoid process and the vertical line of the anterosuperior border of the $\mathrm{C} 3$ vertebral body.

In our research, the consent statement is not required because our research is a retrospective imaging studies which retrieve existing imaging data from The Picture Archiving and Communication Systems (PACS) of our hospital.

\section{Statistical methods}

All statistical analyses were performed with SPSS 17.0 software (IBM, Armonk, NY, USA). Data were analyzed using independent samples $t$-tests, with statistical significant represented by $\mathrm{P}<0.05$.

\section{Results}

There were no significant differences between males and females in group A, group B, or group C. The mean value of parameter D in group A was $4.21 \pm 1.62 \mathrm{~mm}$, which was not sufficient to accommodate a single screw. In group B, the mean value of parameter $\mathrm{D}$ was $5.50 \pm 2.80 \mathrm{~mm}$ (Table 1); however, the diameter varied widely among individual patients in this group. In group C, the mean value of parameter D was $8.64 \pm 1.68 \mathrm{~mm}$, which is similar to that of adults. The values of the parameters $\mathrm{AB}$ and $(\alpha)\left(^{\circ}\right)$ were lower than those for adults.

The mean value of parameter $\mathrm{A}$ in groups $\mathrm{A}, \mathrm{B}$, and $\mathrm{C}$ 
was $4.40 \pm 1.93,6.56 \pm 1.98$, and $9.50 \pm 1.91 \mathrm{~mm}$, respectively. The mean value of parameter $\mathrm{OB}$ in groups $\mathrm{A}, \mathrm{B}$, and $\mathrm{C}$ was $3.34 \pm 0.62,5.90 \pm 0.80$, and $9.90 \pm 1.71 \mathrm{~mm}$, respectively. The mean value of parameter $\mathrm{AB}$ in groups $\mathrm{A}, \mathrm{B}$, and $\mathrm{C}$ was $12.69 \pm 2.20,16.41 \pm 6.52$ and $18.69 \pm 1.98 \mathrm{~mm}$, respectively (Table 1). The measurement values of parameters D, A, $\mathrm{OB}$, and $\mathrm{AB}$ increased with age. There was a statistically significant difference across age groups $(\mathrm{P}<0.05)$. The mean value of parameter $\left(\alpha^{\circ}\right)$ in groups $\mathrm{A}, \mathrm{B}$, and $\mathrm{C}$ was $19.71 \pm 1.85$ $\left(\alpha^{\circ}\right), 21.49 \pm 2.18\left(\alpha^{\circ}\right)$, and $22.06 \pm 1.88\left(\alpha^{\circ}\right)$ (Table 1), respectively; however, the differences between the groups were not significant $(\mathrm{P}>0.05)$.

\section{Discussion}

In children with cervical injuries, the possibility of simultaneous odontoid fractures must be considered. To date, a consensus regarding treatment for odontoid fractures has yet to be reached. Traditional non-surgical treatments include halo-vest frame and plaster external fixation. The non-fusion rate reaches $26-80 \%$ (8). It is generally considered that Anderson type II and superficial type III odontoid fractures are unstable $(8,9)$, and there are clear indications for surgery. We used to take the posterior atlantoaxial fusion for the treatment of unstable odontoid fractures, the fusion rate is between $80-100 \%$, and the neck rotation activity after the operation is reduced by $50 \%$, and the flexion and extension activities are reduced by $10 \%$ (10). The atlantoaxial joint was immediately stabilized when the direct anterior screw fixation was used for the treatment of odontoid fractures, and its cure rate was similar to that of posterior fusion, and $83 \%$ of patients retained normal cervical spine movement (11). The Anderson and D'Alonzo (12) classification of odontoid process fractures can be used in children. Type I odontoid fractures are rarely detected due to their good stability, and the treatment outcomes for these simple breaks are good over two or three months. Type III odontoid fractures are more severe but can heal almost completely. At present, a large amount of controversy exists regarding the optimal treatment for type II fresh odontoid fractures. For Anderson type II fractures, many scholars emphasized that anterior screw internal fixation should be determined according to the fracture line direction $(5,13)$. Eysel and Roosen divided Anderson type II odontoid fractures into type 3 according to the fracture line direction on the sagittal plane, and the type A fracture line is horizontally, the type B is inclined forward upward to backward downward, and the type $\mathrm{C}$ is inclined upward forward downward. It is believed that because the fracture line of type IIC is in the same direction as the screw, due to the shear stress of the fracture end, the fracture may be displaced again or false joint formation, so direct anterior screw internal fixation is not suitable. Proactive surgical treatment is usually advised, because conservative treatment often fails, resulting in the optimal time for treatment being missed. With our research, we hope to provide reference information with CT measurements for the use of anterior percutaneous screw fixation in children of different age groups.

Jagannathan and Bailey et al. $(6,14)$ showed that there are 5 original axial ossification centers: (I) located in the cervical vertebral body, (II) located in the odontoid process, and (III) located in the cervical arch. As explained by Ogden (15), fusion occurs between the odontoid and C2 vertebral body at 6 years of age and between the apex of the dens and the odontoid at 12 years of age. The children in our study were divided into 3 groups according to age, which correspond to the developmental stages of the cervical spine.

As previously reported in the literature, children with odontoid fractures are usually given conservative treatment, and surgery is only used in failed procedures. Due to the instability of atlantoaxial fractures in children, odontoid fractures are not uncommon and can result in spinal instability and spinal cord injury. Therefore, targeted treatments for pediatric odontoid fractures need to be developed (16). Relative to the anterior screw fixation, posterior fusion is associated with a higher fusion rate but reduces cervical rotation by $50 \%$ and flexion-extension by $10 \%$ (10). In 2005, Jones et al. (17) reported a case of pediatric odontoid fracture for which conservative treatment had failed, with no fusion. Subsequently, the authors used percutaneous screw fixation, yielding satisfactory results after 5 months of follow-up. However, the authors suggested that percutaneous screw fixation should not be used for oblique fractures of the odontoid; instead, they put forward the use of posterior fusion methods. These treatment principles were consistent with Chi's view on adult odontoid fractures (18).

The percutaneous lag screw diameter depends on the minimum distance of the odontoid cross-section. According to our research results, the odontoid cross-sectional transverse diameter is smaller than the longitudinal diameter; therefore, the diameter of the screw depends on the odontoid transverse diameter. Furthermore, 
biomechanical studies $(4,19,20)$ have confirmed that singlescrew and double-screw fixation have the same effect on shear stiffness (bending) and torsional stiffness, with both methods providing the same level of stability. Our measurement results showed that in children of less than 6 years old, the coronal external diameter of the base of the odontoid was $4.21 \pm 1.62 \mathrm{~mm}$, meaning a single screw could not be accommodated without the odontoid splitting. Therefore, we do not recommend the use of anterior screw fixation in children under the age of 6 years old, and conservative treatment, such as the halo vest, should be the first-line treatment for this age group. For 6- to 12 -year-old children, the mean diameter was $5.50 \pm 2.80$ $\mathrm{mm}$ and was highly variable. Therefore, if conservative treatment produces poor results, anterior screw fixation is the optimum treatment strategy, but it must be performed on the basis of individual CT measurements, due to the high inter-individual variability in children. Posterior spinal arthrodesis is the secondary option. For 12- to 18-year-old children, the coronal external diameter of the base of the odontoid, at $(8.64 \pm 1.68) \mathrm{mm}$, was close to that of adults; therefore, for this age group, we recommend anterior screw fixation for the treatment of odontoid fractures, to improve patients' quality of life and reduce the risk of related complications.

The screw implantation angle and length are other important parameters that influence the success of surgery. Screws with angles and lengths that are too small do not provide stable fixation, which can easily lead to the cortical bone splitting; meanwhile, screws with angles and lengths that are too large can cause odontoid tip fracture separation or spinal cord injury. Therefore, the implantation angle must be determined using the reclining angle of the odontoid and the diagonal angle of the odontoid sagittal plane. For 6- to 18-year-old children, the odontoid angle and length are smaller than those of adults. To put it briefly, inter-individual differences must be considered when anterior screw fixation is used to treat odontoid fractures.

Anterior percutaneous screw fixation has demonstrated good results in the treatment of adult odontoid fractures; however, the use of this technology in children can be dangerous due to the strong forces generated by screw fixation. Therefore, when performing anterior percutaneous screw fixation in children, we must consider age-related differences in parameters and select the appropriate screw diameter, length, and implantation angle to ensure the operation is performed safely. Through this, the success rate and quality of life of patients can be improved.

\section{Acknowledgments}

Funding: None.

\section{Footnote}

Reporting Checklist: The authors have completed the STROBE reporting checklist. Available at http://dx.doi. org/10.21037/tp-21-101

Data Sharing Statement: Available at http://dx.doi. org/10.21037/tp-21-101

Conflicts of Interest: All authors have completed the ICMJE uniform disclosure form (available at http://dx.doi. org/10.21037/tp-21-101). The authors have no conflicts of interest to declare.

Ethical Statement: The authors are accountable for all aspects of the work in ensuring that questions related to the accuracy or integrity of any part of the work are appropriately investigated and resolved. All procedures performed in this study involving human participants were in accordance with the Declaration of Helsinki (as revised in 2013). The study was approved by Ethics Committee of the Second Affiliated Hospital of Wenzhou Medical University (No.: 2021-K-09-01). In our research, the consent statement is not required because our research is a retrospective imaging studies which retrieve existing imaging data from Picture Archiving and Communication Systems of our hospital.

Open Access Statement: This is an Open Access article distributed in accordance with the Creative Commons Attribution-NonCommercial-NoDerivs 4.0 International License (CC BY-NC-ND 4.0), which permits the noncommercial replication and distribution of the article with the strict proviso that no changes or edits are made and the original work is properly cited (including links to both the formal publication through the relevant DOI and the license). See: https://creativecommons.org/licenses/by-nc-nd/4.0/.

\section{References}

1. Fassett DR, McCall T, Brockmeyer DL. Odontoid synchondrosis fractures in children. Neurosurg Focus 2006;20:E7.

2. Jones TM, Anderson PA, Noonan KJ. Pediatric cervical 
spine trauma. J Am Acad Orthop Surg 2011;19:600-11.

3. Platzer P, Thalhammer G, Ostermann R, et al. Anterior screw fixation of odontoid fractures comparing younger and elderly patients. Spine (Phila Pa 1976) 2007;32:1714-20.

4. Sasso R, Doherty BJ, Crawford MJ, et al. Biomechanics of odontoid fracture fixation. Comparison of the oneand two-screw technique. Spine (Phila Pa 1976) 1993;18:1950-3.

5. Apfelbaum RI, Lonser RR, Veres R, et al. Direct anterior screw fixation for recent and remote odontoid fractures. J Neurosurg 2000;93:227-36.

6. Jagannathan J, Dumont AS, Prevedello DM, et al. Cervical spine injuries in pediatric athletes: mechanisms and management. Neurosurg Focus 2006;21:E6.

7. Fernandes LG, Cristante AF, Marcon RM, et al. Feasibility of anterior screw fixation in children: a tomographic study. Eur Spine J 2018;27:1388-92.

8. Maak TG, Grauer JN. The contemporary treatment of odontoid injuries. Spine (Phila Pa 1976) 2006;31:S53-60.

9. Fountas KN, Kapsalaki EZ, Karampelas I, et al. Results of long-term follow-up in patients undergoing anterior screw fixation for type II and rostral type III odontoid fractures. Spine (Phila Pa 1976) 2005;30:661-9.

10. White III AA, Panjabi MM. Clinical biomechanics of the spine. 2nd ed. Philadelphia: JB Lippincott; 1990:60-611.

11. Nakanishi T. Internal fixation for the odontoid fracture. Orthop Trans 1982;6:179.

12. Anderson LD, D'Alonzo RT. Fractures of the odontoid

Cite this article as: Dou H, Xie C, Zhu S, Wang X, Huang Q, Zhou F. Feasibility analysis of the use of anterior screw fixation in the treatment of pediatric odontoid fracture. Transl Pediatr 2021;10(4):967-972. doi: 10.21037/tp-21-101 process of the axis. J Bone Joint Surg Am 1974;56:1663-74.

13. Eysel P, Roosen K. Ventral or dorsal spondylodesis in dens basal fracture--a new classification for choice of surgical approach. Zentralbl Neurochir 1993;54:159-65.

14. Bailey DK. The normal cervical spine in infants and children. Radiology 1952;59:712-9.

15. Ogden JA. Radiology of postnatal skeletal development. Skeletal Radiol 1984;12:169-77.

16. Crockard HA, Heilman AE, Stevens JM. Progressive myelopathy secondary to odontoid fractures: clinical, radiological, and surgical features. J Neurosurg 1993;78:579-86.

17. Jones A, Mehta J, Fagan D, Ahuja S, Grant A, Davies P. Anterior screw fixation for a pediatric odontoid nonunion: a case report. Spine (Phila Pa 1976) 2005;30: E28-30.

18. Chi YL, Wang XY, Xu HZ, et al. Management of odontoid fractures with percutaneous anterior odontoid screw fixation. Eur Spine J 2007;16:1157-64.

19. Graziano G, Jaggers C, Lee M, Lynch W. A comparative study of fixation techniques for type II fractures of the odontoid process. Spine (Phila Pa 1976) 1993;18:2383-7.

20. Nucci RC, Seigal S, Merola AA, et al. Computed tomographic evaluation of the normal adult odontoid. Implications for internal fixation. Spine (Phila $\mathrm{Pa}$ 1976) 1995;20:264-70.

(English Language Editor: J. Reynolds) 